\title{
Authentic - False. Correlation between Graphics and Physico-Chemical Painting Techniques Expertise in Artwork Analysis
}

\author{
Georgiana Mardare (Bălușescu) ${ }^{1}$, Nicoleta-Elena Hegheș ${ }^{2}$ \\ I "Gheorghe Asachi" Technical University of Iași, Iași, Romania, georgiana.balusescu@tuiasi.ro \\ 2 ,Dimitrie Cantemir" Christian University,Bucharest, Romania,nicoleta.heghes@ucdc.ro
}

\begin{abstract}
Art is a specific human activity that aims at producing aesthetic values and using specific means of expression. Moreover, arts are distinguished by the material used (painting - color, sculpture - stone or wood, literature - words, music - sound or note), but they share the artistic image underlying the act of creation. Authentic - False in artworks should not only focus on the substrate, the paints, the background, the lacquer, but also on the technique used to verify that it corresponds to that of the painter. The resolution of these problems cannot be conceived without the use of laboratory techniques that reflect a predominant place in the observations of the person skilled in the art. Therefore, the identification of technical investigations should be carried out systematically for each expertise. These expertises can be simple, convenient and efficient. In this paper is presented an overview of trace evidence and chemical painting techniques used in artwork and the applicability of chromatography, spectroscopy, X-ray radiography, neutron autoradiography and conoscopic holography as a tool for investigations of the material composition of the paintings. X-ray radiography and neutron autoradiography, for example, are nondestructive techniques which enable determination the structure of the components and also the material composition. The applications of these techniques answer the questions when, where, or by whom such a painting was made.
\end{abstract}

KEYWORDS: analytical techniques, signatures authenticity, neutron autoradiography, X-ray radiography, trace evidence

\section{Introduction}

The signature first appeared on works of art during the Renaissance, when the artistic product changed from the collective result of some artisans into the product of individual creativity. The signature thus became the way of differentiating the artist's talent from his fellow colleagues. Sometimes the signature is part of the creation process, and the artist uses it as the end of a work, as a note that tells him that he no longer has to interfere with the work. In some cases, the signature also contains the date or location of the work, the name chosen by the artist, or any other information, even the paint used. As time passes, the signatures may blur or wipe, becoming visible only in ultraviolet light or even at the microscope. The signature can also be misleading. The mere existence, however convincing of a signature, does not mean that the work belongs to the artist. There are also cases in which the artist left the work unsigned, and then the owner applied a signature to highlight the paternity of the work. And there are, of course, cases of falsification of works of art when an artist makes a convincing copy of a work and signs it using the signature of the original author. Detecting false signatures can be done with the naked eye by an expert familiar with the artist, in general the falsified signature being more carefully executed than assuming the unintentional of a signature of its own name. Subsequent signatures can easily be identified with ultraviolet light, the newer pigment shining. There are, however, artists who have never signed a work, which can be a signature in itself. Finally, the best sign of a work is the work itself, the style, the ink, the themes etc., which are the elements that define the artist to an extent at least as great as his signature (Christie's 2018).

Proof of authenticity can be accomplished in several ways, including forensic expertise. In judicial proceeding, there are more and more cases of arrangement and implementation of: a) Graphical expertise that focus on establishing the authenticity of signatures on paintings or sculptures; b) Physico-chemical expertise on the composition, properties and age of the materials used for the performance of the artistic work; c) Traseological expertise covering an extended range of objectives that differ from the peculiarities of the investigated cases (Pășescu and Chende 2009, 110-111). 


\section{Graphics expertise that focus on establishing the authenticity of signatures found on paintings or sculptures and physico-chemical expertise on the composition, properties and age of the materials used to perform the artistic work}

A distinct place in order to identify or establish the origin of material evidence or traces of various materials is occupied by methods of spectral analysis. "The basis of those methods is the relationship between matter and radiation" (Stancu 2010, 7-9).

Electromagnetic radiation, either emitted or absorbed by a substance or element, is specific to each type of molecule or atom, their characteristics resulting from the wavelength of the radiation, the number, intensity, and grouping of the spectral lines. The electromagnetic radiation used in spectral analyzes includes a very wide range, including both visible and invisible radiation: $\mathrm{X}$, ultraviolet and infrared radiation. Infrared radiation is widely used in the forensic search of documents because of the property they have to be absorbed by ink and opaque graphite and carbon layers or for pigments that are comprised of copying paper and pigments. Luminescence examination is among the methods currently used in forensic research, sometimes even on the spot, due to its simplicity, rapidity and sensitivity. The utility of the method also resides in the fact that it requires very small quantities or concentrations of the substance. Luminescence, in the form of photoluminescence phenomenon, is a light radiation emission by a body as a result of its excitement by another electromagnetic radiation, visible or invisible (ultraviolet or infrared). Parallel to the phenomenon of fluorescence as such, research also explores the phenomenon of extinction of fluorescence, which can be determined by the action of a certain body or substance or the action of infrared radiation and which is applicable to the investigation of documents. Luminescence analysis has been in use since the beginning of this century and finds its applicability in the investigation of forgery, document material (paper and ink) (Stancu 2010, 340-342; Stoian 2013, 375-393).

An example is the artwork of Maurice Utrillo. Utrillo often included the initial "V" for Valadon after Utrillo: "Maurice Utrillo V." (Figure 1.a). In many cases Utrillo included the year (Figure 1.b). and sometimes even the month. (Figure 1.c). Utrillo did sometimes use the shorter form "M. Utrillo" with no date, though the former example is the most common (Figure 1.d) (Utrillo Experts Authentication 2019).

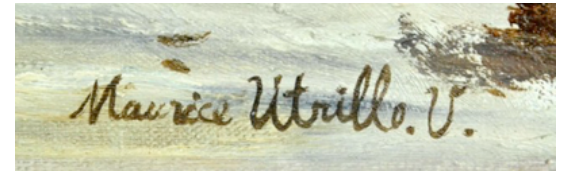

(a)

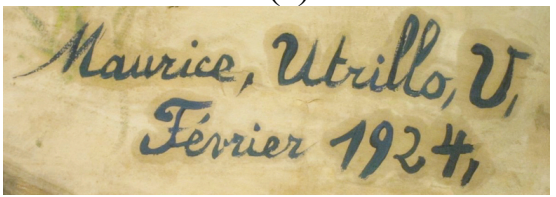

(c)

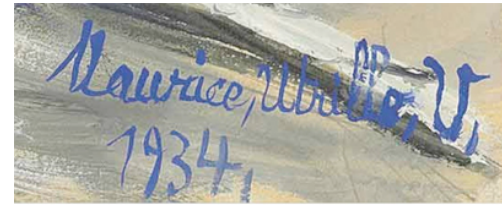

(b)

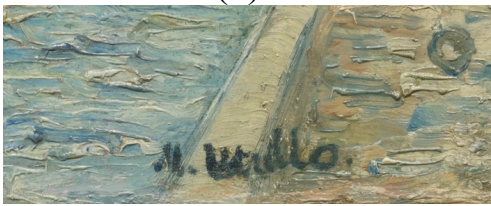

(d)

Figure 1. Different Maurice Utrillo Signatures

A first examination was done with direct light. For a first observation, the reference element contained in the painting is not visible. A second examination was performed with dark light. This is done in ultraviolet light using a source emitting at $254 \mathrm{~nm}$. (short wavelength) or $356 \mathrm{~nm}$. (long wavelength). Many ultraviolet absorbers pigments and some of this energy disperse as viscous variable colour with higher wavelengths and low energy. The further the fluorescence continues, the ultraviolet emission disappears. Ultraviolet illumination at short or long wavelengths collects fluorescence in the visible spectrum. Some examples of fluorescent pigments: a) Aluminium Hydroxide - Clear Blue; b) Calcium (powder) - From red to brown; c) Calcium (silica) - Red-violet; d) Magnesium carbonate - Violet; e) Magnesium Oxide - BlueGray; f) Lead White - Red-Brown; g) Zinc Sulphide - Orange; h) Zinc White - Light Yellow.

Infrared analysis allows you to see the original design, the outlines, the first layers of paint, and sometimes to identify a repaired signature. Like ultraviolet, infrared emission can absorb some of the pigments. The luminescence can be seen through a suitable stop filter. For example: the yellow filter 
shades yellow, the red and green filters scumble blue and purple; the blue filter shades blue and purple and scumble greenish-yellowish and red; the green filter shades green and yellow and scumble violet and red; the red tint shades red and yellow and scumble green, blue and purple.

From the infrared analysis of Maurice Utrillo's paintings we can see that the repaired layers absorb at wavelengths starting at $645 \mathrm{~nm}$, and the word (signature) on the picture becomes clearer at wavelengths of $745 \mathrm{~nm}$.

The ultraviolet and infrared examination did not give convincing results about authenticity and age, which is often the case with this type of examination. The fluorescence of the coating that has nothing to do with painting itself is almost always strong. Analysis of the colour shade in visible light and ultraviolet absorption are not always sufficient for identification.

\section{X-ray radiography}

Another method of analysis is X-ray radiography that allow in-depth examination of the cloth and highlight the layers of paint (stratification). It is known that different metals, for example Lead, are opaque to the X-ray analysis. It will result that the area of the paint containing Lead will correspond to a blacksilver stain. On the contrary, mixing paint of plant origin by X-ray analysis will correlate to a white (clear) area. According to the radiographic record, we can say that it has analogies with authentic X-ray.

In an X-ray analysis of Van Meegeren's painting, we can see that under the painting layer one can see a scene of a herd of horses (Figure 2).

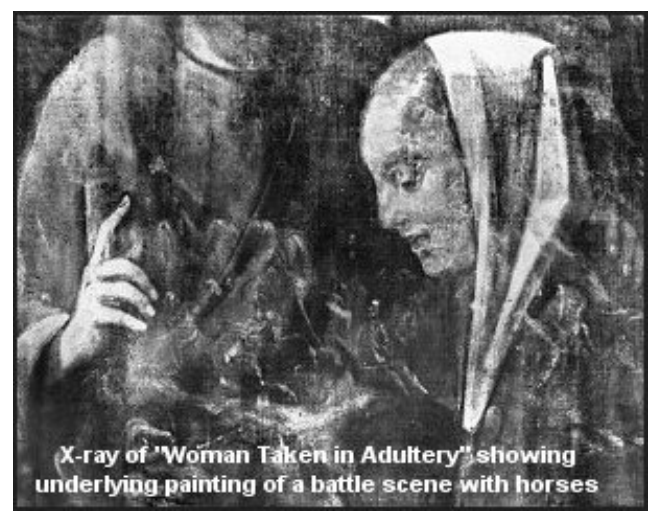

Figure 2. The Woman taken in Adultery paint by Van Meegeren photographed to reveal the various paint-layers (Detection of the Fakes 2019)

Scripture materials are generally composed of dyes, pigments, solvents, resins, and other specialty materials. Ink analysis, for example, is currently limited to comparing the profile of organic dyes. However, this does not allow differentiation between inks with similar formulas and does not allow forensic experts to specify how long ink has been applied to a document. To distinguish inks, it is necessary to analyze their uncoloured components, namely: solvents, additives, fillers. They can be analyzed by direct thermal desorption of paper samples, followed by chemical analysis of volatile compounds desorbed by mass spectrometry gas chromatography. Moreover, the age of scriptural materials applied on the same type of paper with the same scriptural material can be investigated by LC-MS technique by quantifying the ink components and investigating their degradation products.

The Van Meegeren business is the most discussed case in the world of art lovers. I will make a brief introduction on this case and then introduce other authentic-false analysis techniques in his works.

In 1932, Van Meegeren moved with his wife to Italy. There he rented a furnished mansion called "Primavera", where he settled down. Here he set out the chemical and technical procedures that would be needed to create "perfect fake". He bought authentic $17^{\text {th }}$-century cloth and mixed his own paints from raw materials (such as lapis lazuli - blue precious stone, white lead, indigo and cinnabar - mercury sulphide), using old formulations to ensure that they were genuine. He also used badge hair brushes, similar to those of Vermeer, for which he was recognized for their use. He used a system to make the canvas look old, using phenol formaldehyde (Bakelite), in order for the paints to harden after application. This makes the 
paintings look 300 years old. After finishing Van Meegeren's baking in an oven at $100^{\circ} \mathrm{C}$ to $120^{\circ} \mathrm{C}$ to cure the paint, then roll it over to a cylinder to form cracks. The next step was to wash the black ink cloth from India to fill cracks (Figure 3). Van Meegeren took six years to prepare this technique(Robert 2013; Wikipedia 2019).

A committee has examined eight paintings painted by Vermeer and Frans Hals, paintings that have been identified as forgeries. With the help of the commission, Dr. Coremans was able to determine the chemical composition of the paint used by Van Meegeren. He discovered that Van Meegeren prepared paints by mixing them with a plastic binder, Albertol which is a phenol resin. A bottle of this ingredient was found in his studio (Figure 4).

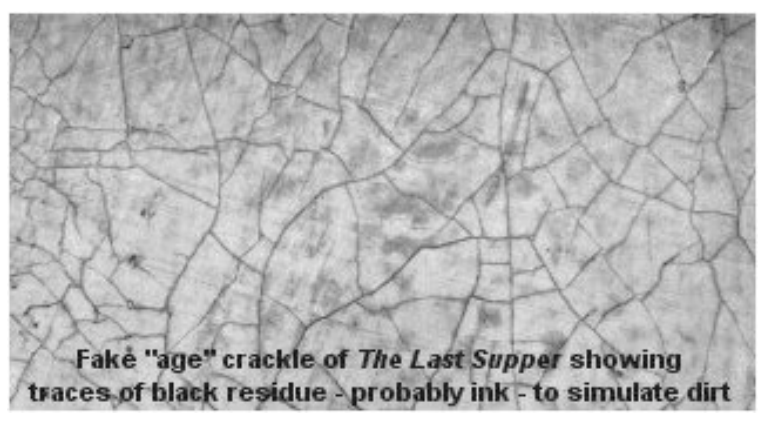

Figure 3. Fake Age Cracks

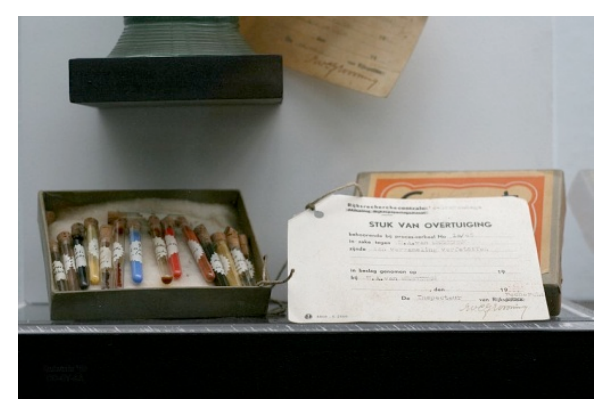

Figure 4. Evidence Against Han van Meegeren: A Collection of Pigments

This chemical component was introduced and manufactured in the $20^{\text {th }}$-century, proving that the "Vermeer" and "Frans Halses" fake works examined by the Commission were actually made by Van Meegeren. Other Commission findings have suggested that the dust from the cloth cracks was too homogeneous to be of natural origin. The problem found in cracks appeared to come from India ink, which was accumulated even in areas where physical dirt or dust would not have arrived.

The paint became so strong that neither strong acids nor strong bases attacked the surface when carrying out chemical analyzes, which led to a clear indication that the surface was not processed in a natural way. Thus, the results of the tests obtained by the Commission seem to confirm that the works were fakes created by Van Meegeren, but their authenticity has been debated by some experts until 1967 and 1977, when they used new investigative techniques to analyze the paintings.

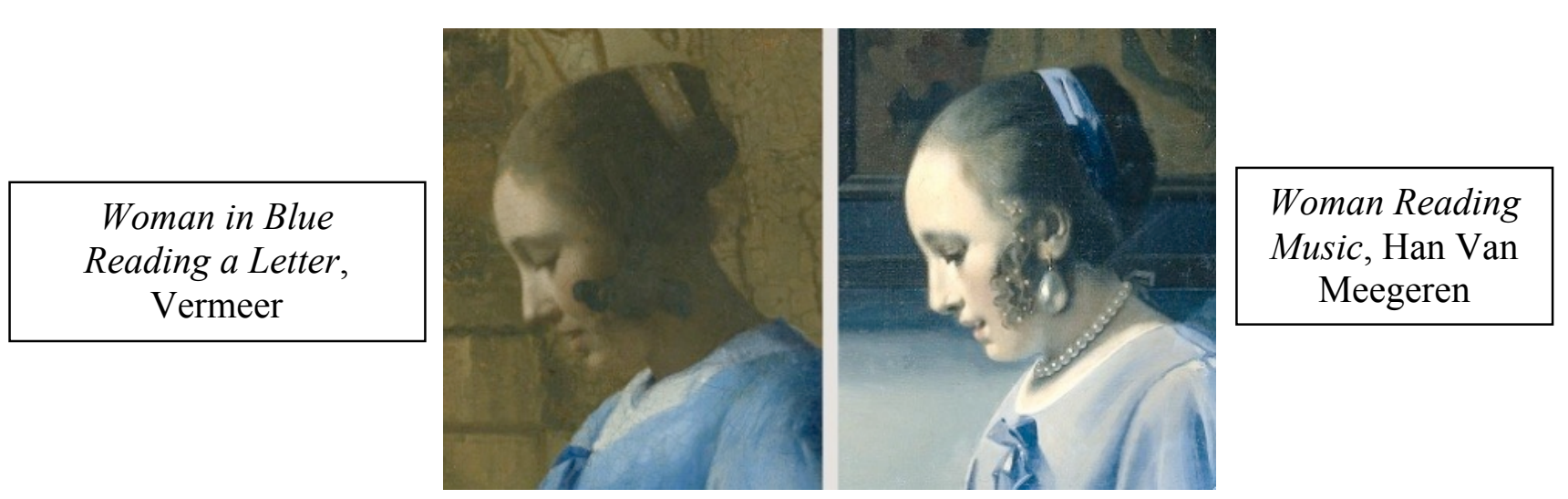

Figure 5. Details about the "woman" characteristics of Vermeer's paintings (Left) and Van

$$
\text { Meegeren (right) }
$$

In 1977 another investigation was conducted by the forensic laboratories in the Netherlands using gas chromatography to officially confirm the origin of six Van Meegeren fakes, including "Emmaus" and "The Last Supper", which was claimed to be genuine Vermeer. The 1946 commission's conclusions were again reaffirmed and supported by the Dutch judiciary. According to expert Jonathan Lopez, the technical 
failures of the image are largely due to the use of the new material counterfeiter, Bakelite, which would be resistant to the alcohol test that was used for false unfolded paintings whose paint was not allowed enough time to get strong. However, paints mixed with Bakelite have been much harder to achieve than traditional oil paints that are easy to mix, dry out slowly and allow the painter to take on shapes and shades of light. In order to better master the technique, Van Meegeren began to study architecture, making him a "strange perfectionist". Fearing technical examinations, Van Meegeren painted images of $17^{\text {th }}$-century methods and materials and anticipated all the tests that could be used to discover his deeds. He used a cloth and pigments such as natural, cinnamon and white lead of the 17th century (Wikipedia 2019).

Details about the "woman" characteristics of Vermeer's paintings (Woman in Blue Reading a Letter) and Van Meegeren (Woman Reading Music). By joining the images we can see that in an attempt to make the fake as credible as possible, Van Meegeren added a large pearl and a pearl necklace, both props are repeatedly represented by Vermeer. Although Van Meegeren's modeling of the head is more subtle than that of Vermeer, it should be borne in mind that Van Meegeren had to mix the pigments with a synthetic, Bakelite, quick-drying, allowed to merge with its paints, this being done to hide that they were freshly dyed (Vermeer: Erroneous Attributions and Forgeries 2019).

Han Van Meegeren knew that Lead White was used during Vermeer's time but he had to get his stocks through trade by buying modern paint that have changed significantly since the $17^{\text {th }}$-century. During Vermeer's time, Dutch lead was extracted as ore from the Netherlands. However, by the 19th century, most Lead White was imported from Australia and the Americas. Dutch lead was extracted from ores containing high levels of silver and antimony trace elements, while the modern lead white used by Van Meegeren contained neither silver nor antimony. These elements are separated from lead during the modern melting process.

\section{Neutron autoradiography}

Activation analysis is one of the most modern methods of research, characterized by both sensitivity and precision superior to other analytical methods. In addition, it has the advantage of being a non-destructive method, as with X-ray diffraction. Although seemingly simple, it is applied in practice with some difficulty requiring the use of top techniques. Activation analysis consists in irradiating an amount of analyte to obtain radioactive isotopes of the elements found in its mass. It is a method of qualitative and quantitative analysis - based on the property of radioactive isotopes. Activation analysis is a method of elementary investigation. After irradiation, the elements emit radiation with certain energies on which the radioactive isotopes formed can be identified and the percentage they are found in. Before the chemical analyzes used to identify forgery were destructive methods: small fragments of the investigated works were cut and analyzed; it was often not possible to conduct investigations to preserve the integrity of the object (Ainsworth et al. 1987, 13-18; Humelnicu 2017, 77-79).

In the Middle Ages, Lead White was used in painting and the impurities contained therein can provide information about the age of painting. Neutron activation analysis performed on 1800-1875 dye samples and nowadays shows that the concentrations of all elements in the $\mathrm{Pb}$ white are different. Until $1850, \mathrm{Cu}, \mathrm{Ag}, \mathrm{Hg}$ and $\mathrm{Mn}$ concentrations were relatively high and constant, after which they dropped to about one tenth of the initial value. On the other hand, zinc and antimony concentrations increased sharply after 1940 (Table 1). As well as the applications of the technique there are: 1) Pigment analysis by activation technique and, 2) Neutron absorption radiography - autoradiography (Ainsworth et al. 1987, pp. 9-13).

Neutron irradiation of the whole painting uses a homogeneous stream of neutrons, followed by measurement of activity (Humelnicu 2017, 77-79; Neutron activation of paintings, 2019).

\section{X-rays show us the pigment position $\gamma$-rays gives us the pigment characteristics}


Table 1. Chemical Elements and Associated Pigments Most Frequently Observed in Autoradiography of Seventeenth-Century Dutch and Flemish Paintings

\begin{tabular}{|c|c|c|c|}
\hline Chemical elements & Associated pigments & $\begin{array}{l}\text { Radioactive isotope } \\
\text { formed during } \\
\text { activation and its } \\
\text { half-life }\end{array}$ & $\begin{array}{l}\text { Time period after } \\
\text { activation during which } \\
\text { best images in } \\
\text { autoradiographs are } \\
\text { produced }\end{array}$ \\
\hline Manganese (Mn) & umber, dark, ocher & ${ }^{56} \mathrm{Mn}(2,6$ hours $)$ & $0-24$ hours \\
\hline Copper $(\mathrm{Cu})$ & $\begin{array}{l}\text { malachite, azurite, } \\
\text { verdigris }\end{array}$ & $\begin{array}{l}{ }_{66}^{66} \mathrm{Cu}(5,1 \text { minutes }) ; \\
{ }^{64} \mathrm{Cu} \text { (12,8 hours) }\end{array}$ & $\begin{array}{l}0-20 \text { minutes } \\
1-3 \text { days }\end{array}$ \\
\hline Sodium $(\mathrm{Na})$ & $\begin{array}{l}\text { glue, medium, } \\
\text { canvas, ultramarine }\end{array}$ & ${ }^{24} \mathrm{Na}(15$ hours $)$ & 1-3 days \\
\hline Arsenic (As) & smalt, glass & ${ }^{76}$ As $(26,5$ hours $)$ & 2-8 days \\
\hline Phosphorus (P) & bone black & ${ }^{32} \mathrm{P}(14,3$ days $)$ & 8-30 days \\
\hline Mercury (Hg) & vermilion & ${ }^{203} \mathrm{Hg}$ (48 days) & $>25$ days \\
\hline Cobalt (Co) & smalt, glass & ${ }^{60}$ Co (5,3 years) & $>25$ days \\
\hline
\end{tabular}

Examples:

In Figure 6 is represented Anthony van Dyck, Saint Rosalie praying for the Plague stricken of Palermo Painting, 1624, which reveald Pigment Identification by Analysis of Time Dependence for Characteristic Activity
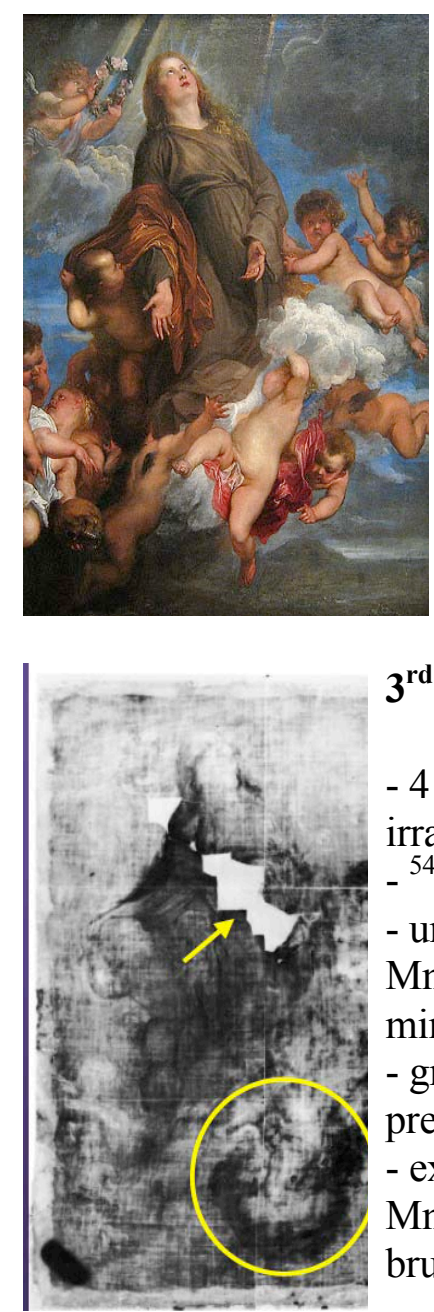

\section{Original Painting}

\section{$3^{\text {rd }}$ autoradiograph}

$-4-4,75$ h (after irrad.);

$-{ }^{54} \mathrm{Mn}, \mathrm{t}_{1 / 2}-2,6 \mathrm{hr}$; - umber- $\mathrm{Fe}_{2} \mathrm{O}_{3}+$ $\mathrm{MnO}+$ clay

minerals; - ground, preliminary sketch; - exposure reveals Mn position, brushstrokes.

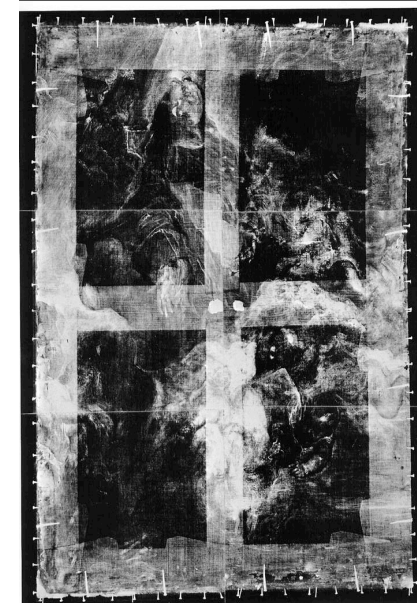

Radiograph

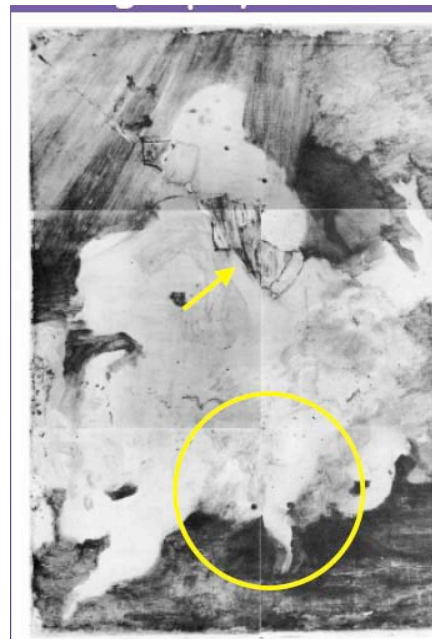

$6^{\text {th }}$ autoradiograph

- 2-4 d after irrad.;

$-{ }^{64} \mathrm{Cu}, \mathrm{t}_{1 / 2}-12,8 \mathrm{hr}$;

- azurite - $\mathrm{CuCO}_{3}$

. $\mathrm{Cu}(\mathrm{OH})_{2}$;

${ }^{24} \mathrm{Na}, \mathrm{t}_{1 / 2}-15 \mathrm{hrs}$;

- ultramarine sodium aluminosilicate. 

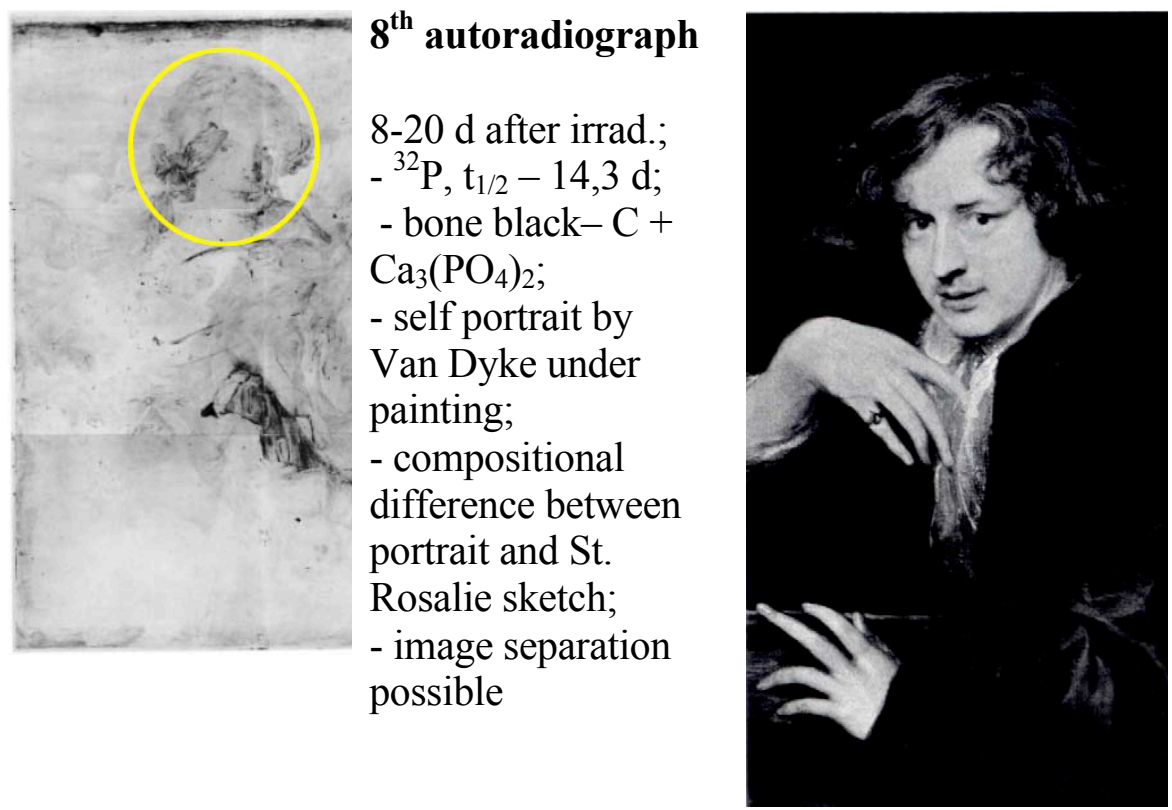

Sir Anthony van

Dyck

Self Portrait, 1622

Figure 6. Pigment Identification by Analysis of Time Dependence for Characteristic Activity $3^{\text {rd }}, 6^{\text {rd }}, 8^{\text {rd }}$ Runs of Anthony van Dyck, Saint Rosalie Praying for the Plague Stricken of Palermo

Painting, 1624 (Ainsworth et al. 1987, 13-18; Neutron activation of paintings 2019).

\section{Conoscopic holography}

A new method for recording holograms using incoherent light is described. The method is based on optical propagation through birefringent crystals. Optical methods for the reconstruction of such a hologram are also presented (Sirat and Psaltis 1985, 4).

Francesco Dellavalle, electronics technician in Torino, the founder of FORINST (Forensic Instruments), has almost three decades of experience in 2D/3D dimensional and surface measurement systems that were not in contact with research and industry. In 1988 he approached the first morphological analyzes of graphs by optical microscopy and image processing. More passionate about the subject, in 2001 he is the creator of the "interferential method" (through conoscopic holography) in order to objectively apply the order of application of graphs intersecting with each other Thanks to an innovative technology (laser profiling based on conoscopic holography, which currently holds seventeen patents, six of which worldwide), three-dimensional scans of ancient documents, bas-reliefs, statues, papyruses, jewelery etc. can be created either to create a historical archiving, either to make measurements or threedimensional true restorations on plastic or metal. The technique used is not invasive and does not affect objects in any way, both physically and chemically (Dellavalle 2003).

\section{The operating principle of "conoscopic holography" also called "interference method"}

Conoscopic Holography was introduced in 1985 at the California Institute of Technology by Professors Gabriel Sirat and Demetri Psaltis. As mentioned previously, conoscopic holography is a three-dimensional non-contact measurement technique that makes it possible to produce holograms. In synthesis is a simple implementation of a special polarized light interference process using a birefringent crystal (Sirat and Psaltis 1985, 4).

\section{A distinction must be made:}

- In the classical holography, each point of the object is interferometrically recorded as a Fresnel area plate in which the interference plane is formed between the object radius and the reference ray, using a coherent light source. The object's and reference rays propagate at the same speed but follow different geometric paths. 
- In the conoscopic holography, the radius of the object and the reference is replaced by the ordinary and extraordinary components of a single ray propagating in a birefringent center; anyway they have roughly the same geometric trajectory but different speeds. The two rays are of course coherent with each other and thus the technique allows the construction of holograms and light that is not coherent.

Conoscopic holography offers considerable advantages, unlike the classic one, if the target area is spatially limited (one point, a set of discrete points or a continuous line).

\section{Conclusions}

The applications of these techniques answer the questions when, where, or by whom such a painting was made. The broad possibilities of technical-scientific investigation have made some authors claim that discovery of a fake in artwork - and in our opinion not only in this area - represents $1 \%$ intuition and $99 \%$ laboratory work.

\section{References}

Ainsworth, Wynn Maryan, Brealey John, Haverkamp- Begemann Egbert, Meyers Pieter. 1987. Paintings by Van Dyck, Vermeer, and Rembrandt Reconsidered Through Autoradiography, Art and Autoradiography. New York: Metropolitan Museum of Art.

Christie's, 2018. Semnătura operelor de artă (Signature of works of art). Available at https://www.evaluariarta.ro/semnatura-operelor-de-arta/).

Dellavalle, Francesco. 2003. The Grafiscan 3D System and Superposition Pen Strokes, Scrittura issue 126.

Terence Nunn. 2019. Detection of the Fakes. Available at http://www.tnunn.net/index.htm

Humelnicu, Doina. 2017. Tehnici radiochimice utilizate în investigațiile Criminalistice (Radiochemical Techniques Used in Forensic Investigations). Iasi: Stef Publishing House.

Neutron activation of paintings, 2019. University of Notre Dame, https://www3.nd.edu/ nsl/Lectures/phys 10262 /art-chap2-10.pdf.

Pasescu, Gheorghe and Chende Paul. 2009. "Forensic Expertise and the Auctions with Works of Art." Revista de Criminologie, Criminalistică şi Penologie, https://vdocuments.mx/revista-de-criminologie-criminalistica-si-penologie.html.

Sirat, Gabriel and Psaltis Demetri. 1985. Conoscopic Holography, Optics Letters 10: 4-6.

Stancu, Emilian. 2010. Tratat de Criminalistică (Criminalistic Treaty). Bucharest: Universul Juridic Publishing House.

Stoian, Georgeta Maria. 2013. Contribuția expertizei fizico-chimice a probelor materiale la probațiunea juridică. (Contribution of physico-chemical expertise of material evidence to legal probation). Bucharest: Aktis Tipografie Ambalaje.

Utrillo Experts, Authentication and appraisal of Maurice Utrillo paintings, Utrillo Signature Authentication, https://www.utrilloexperts.com/utrillo-signature.html.

Essential Vermeer. 2019. Vermeer: Erroneous Attributions and Forgeries (part two), Woman Playing Music. Available at http://www.essentialvermeer.com/fakes_thefts_school_of_delft_lost_sp/erroneously_attributed_vermeers_two.html \#.XOC19RQzbIU.

Wikipedia. 2019. Han van Meegeren. https://en.wikipedia.org/wiki/Han_van_Meegeren.

Williams, Robert C. 2013. The Forensic Historian: Using Science to Reexamine the Past. Armonk, N.Y.: M.E. Sharpe. 